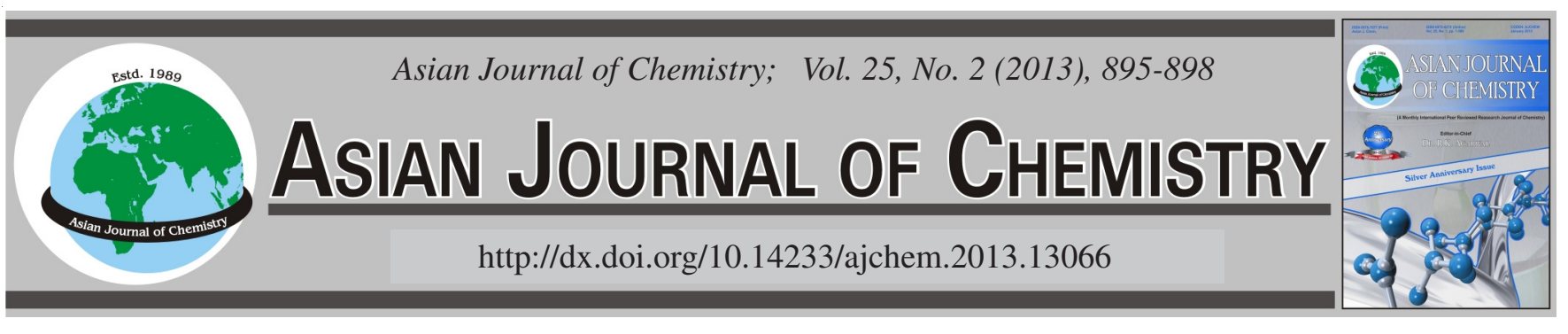

\title{
Mechanical Properties of Two Kinds of 2.5D Quartz $/$ Silica Composites by Silica Sol-Infiltration-Sintering
}

\author{
Yong LiU $^{1}$, JiAnXun Zhu $^{1,2, *}$ and ZhaOFENG CHEN ${ }^{1}$
}

${ }^{1}$ College of Material Science and Technology, Nanjing University of Aeronautics and Astronautics, 29\#, Jiangjun Road, Nanjing 211106, P.R. China

${ }^{2}$ Sinoma Science \& Technology Co., Ltd., Nanjing 210012, P.R. China

*Corresponding author: Fax: +86 25 52112626; Tel: +86 25 52112909; E-mail: jianxun_zhu@163.com

(Received: 15 November 2011;

Accepted: 25 August 2012)

AJC-12005

Two kinds of 2.5D (shallow bend-joint and shallow straight-joint) quartz fiber-reinforced silica composites were prepared by silica solinfiltration-sintering method. Mechanical properties of the composites and the structure characteristics of the 2.5D preforms were compared. The mechanical properties examined included tensile strength, flexural strength and shear strength. The results of the mechanical tests indicated that 2.5D (shallow bend-joint) quartz $/$ silica composite had a higher flexural strength and shear strength than 2.5D (shallow straight-joint) quartz/ $/$ silica composite. The tensile strength of $2.5 \mathrm{D}$ (shallow straight-joint) quartz $\mathrm{f} /$ silica composite were superior to that of $2.5 \mathrm{D}$ (shallow bend-joint) quartz $\mathrm{f} /$ silica composite.

Key Words: Preform, Mechanical properties, Structural characteristics, Stress components.

\section{INTRODUCTION}

Due to high melting point, high thermal shock resistance, low dielectric constant and low loss tangents, amorphous silica have received considerable attraction in the field of missile radomes, heat-resistant materials for aerospacecraft, crucibles and so on ${ }^{1-4}$. However, the intrinsic brittleness and very low fracture strain restrict in many fields for its further applications. Compared with monolithic ceramics, continuous fiberreinforced ceramic matrix composites (CFCCs) have been improved the fracture resistance greatly ${ }^{3,5-8}$. In order to improve the mechanical properties of silica, silica composites reinforced by shorter silica fibers and 2D silica preforms have been investigated. It was showed that the mechanical properties were enhanced. However, there are limits to improve the properties $^{5}$. 2.5D composites were studied in literatures ${ }^{9-14}$. There are a number of $2.5 \mathrm{D}$ structures such as $2.5 \mathrm{D}$ shallow bend-joint, shallow straight-joint, deep straight-joint and so on. The characteristics of $2.5 \mathrm{D}$ weave technique make the fabric preform particularly suitable for conforming to the mould surface of revolving components and allow net or near-net shaping ${ }^{9}$. The 2.5D composites possess higher through-the-thickness mechanical properties as compared to equivalent laminated composites. The 2.5D composites show better delamination resistance and higher interlaminar fracture toughness than traditional laminated composites when subjected to interlaminar stress concentrations. However, limited attention has been focused towards 2.5D quartz fibers reinforced silica composites $\left(Q_{\mathrm{f}} / \mathrm{S}\right)$.

Silica sol-infiltration-sintering (SIS) process could be an appropriate method to fabricate $\mathrm{Q}_{\mathrm{f}} / \mathrm{S}$ due to its effectiveness in relatively low densification temperature, low shrinkage and reduced drying stresses ${ }^{15}$. In order to utilize $2.5 \mathrm{D}$ composites most efficiently, thorough understanding of their mechanical properties is essential. In this paper, 2.5D (shallow straightjoint) preform and $2.5 \mathrm{D}$ (shallow bend-joint) preform were used as the fiber reinforcements. 2.5D composites were prepared by SIS method. The present work has two objectives. The first is to compare the tensile strength, flexural strength and shear strength of the $\mathrm{Q}_{\mathrm{f}} / \mathrm{S}$ with two different reinforcement geometries. The second is to expand the experimental knowledge for how fiber architectures impact mechanical properties.

\section{EXPERIMENTAL}

Composite preparation: The $2.5 \mathrm{D}$ (shallow straightjoint) and 2.5D (shallow bend-joint) woven preforms were provided by Nanjing Institute of Glass Fiber. The geometrical parameters of the $2.5 \mathrm{D}$ preform were listed in Table- 1 . The 2.5D $\mathrm{Q}_{\mathrm{f}} / \mathrm{S}$ composites were prepared by SIS method, which had been already described ${ }^{16-18}$. Most importantly, the sintering temperature was about $450{ }^{\circ} \mathrm{C}$. Compared with the sintering 
TABLE-1

GEOMETRICAL PARAMETERS OF THE 2.5 QUARTZ FIBER PERFORM

\begin{tabular}{lcccc}
\hline \multicolumn{1}{c}{ Fabric types } & Yarn specifications (tex) & $\begin{array}{c}\text { Warp yarn density } \\
\text { (picks/cm) }\end{array}$ & $\begin{array}{c}\text { Weft yarn density } \\
\text { (picks/cm) }\end{array}$ & Fiber volume fraction \\
\hline Shallow bend-joint & $195 \times 2$ & 10 & 4 & $50.5 \%$ \\
Shallow straight-joint & $195 \times 2$ & 10 & 4 & $47.5 \%$ \\
\hline
\end{tabular}

temperature of silica composites from other papers, $450{ }^{\circ} \mathrm{C}$ was a relatively low sintering temperature ${ }^{19,20}$.

Measurement of mechanical properties: Mechanical properties of the composites were characterized under tensile loading, flexural loading and shear loading at warp direction. All the mechanical tests were carried out in a PC-controlled electronic universal testing machine (SANS CMT5105). Tensile test specimens with dimensions of $3.5 \mathrm{~mm} \times 23 \mathrm{~mm} \times$ $94 \mathrm{~mm}$ were cut from the fabricated composite plates and tapered aluminum tabs were glued at both sides to provide a gauge length of $48 \mathrm{~mm}$. Tensile tests were performed at a constant cross-head speed of $0.3 \mathrm{~mm} / \mathrm{min}$. To calculate tensile strength $\left(\sigma_{t}\right)$, the following equation was used:

$$
\sigma_{\mathrm{t}}=\frac{\mathrm{P}_{\mathrm{t}}}{\mathrm{S}}
$$

where $\mathrm{P}_{\mathrm{t}}$ is the maximum tensile fracture load $(\mathrm{N}), \mathrm{S}$ is the cross-sectional area of the specimen.

Flexural strength was measured using the three-pointbending method. The nominal flexural specimen dimensions were $3.5 \mathrm{~mm} \times 5 \mathrm{~mm}$ in cross section and $40 \mathrm{~mm}$ in length. The bending support span size was $30 \mathrm{~mm}$ and the crosshead speed was $0.3 \mathrm{~mm} / \mathrm{min}$. To calculate flexural strength $\left(\sigma_{\mathrm{f}}\right)$, the following equation was used:

$$
\sigma_{\mathrm{f}}=\frac{3 \mathrm{P}_{\mathrm{f}} \cdot \mathrm{L}}{2 \mathrm{~b} \cdot \mathrm{h}^{2}}
$$

where $P_{f}$ is the maximum flexural fracture load $(\mathrm{N}), \mathrm{L}$ is the bending support span size and $\mathrm{b}$ and $\mathrm{h}$ are the width and the height of the specimen, respectively.

Shear strength was measured using the Iosipescu shear testing method, meanwhile, the composite panels were cut into two $45^{\circ}$ Notched ( $5 \mathrm{~mm}$ depth) beam specimens. The nominal shear specimen dimensions were $3.5 \mathrm{~mm} \times 18 \mathrm{~mm}$ in cross section and $80 \mathrm{~mm}$ in length. The loading rate was $0.3 \mathrm{~mm} /$ min. Shear strength $\left(\sigma_{\mathrm{s}}\right)$ was calculated by the following equation:

$$
\sigma_{\mathrm{s}}=\frac{\mathrm{P}_{\mathrm{s}}}{\mathrm{h} \omega}
$$

where $P_{s}$ is the maximum shear fracture load $(N), h$ and $\omega$ are the height and the minimum distance between $\mathrm{v}$-notched of the specimen, respectively. The Archimedes technique was used to determine specimen density.

\section{RESULTS AND DISCUSSION}

Preform structure: Fig. 1 shows the structures of 2.5D preforms. As shown in Fig. 1(a) and (b), the 2.5D preform was a unique kind of multilayer fabric. The structures of the fabrics were markedly different. The preform repeated itself on a certain number of warp and weft yarns. The repeat was a complete representative unit cell of the preform (Fig. 1(c) and (d)). The structural characteristics of 2.5D (shallow bend-joint) preform and 2.5D (shallow straight-joint) preform were: (1) a warp yarn was interlaced with each two weft yarns along the thickness direction; (2) a warp yarn was interlaced with every three or two weft yarns along the weaving direction (2.5D (shallow straight-joint) preform was three and 2.5D (shallow bend-joint) preform was two); (3) the preform was a symmetrical object. The $2.5 \mathrm{D}$ process could produce near-net-shape preforms for components having complicated geometry and thus reduces the production time and associated costs. Especially, this kind of structure could be used to prepare domeshaped components.

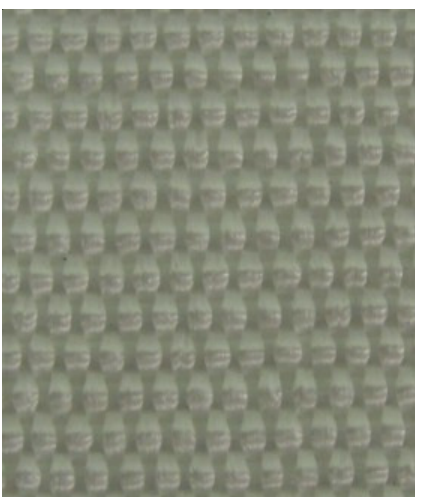

(a) $2.5 \mathrm{D}$ shallow bend-joint quartz preform

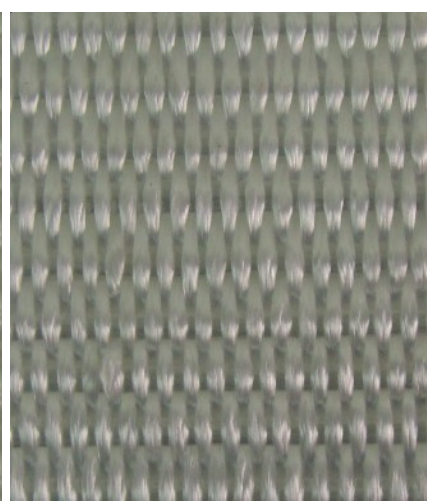

(b) $2.5 \mathrm{D}$ shallow straight-joint quartz preform
Representative Unit Cell

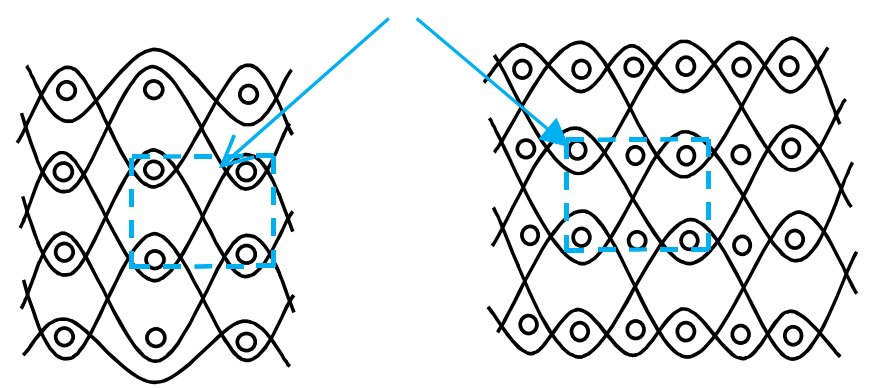

(c) Plane graph of bend-joint preform (d) Plane graph of straight-joint preform Fig. 1. Structures of $2.5 \mathrm{D}$ preform

Mechanical properties: Table-2 shows the mechanical properties of the 2.5D $\mathrm{Q}_{\mathrm{f}} / \mathrm{S}$ composites. The density of the 2.5D (shallow straight-joint) composite and 2.5D (shallow bend-joint) composite were $1.70 \mathrm{~g} / \mathrm{cm}^{3}$ and $1.77 \mathrm{~g} / \mathrm{cm}^{3}$, respectively. Under the same preparation conditions, the densities of the composites were different. The different densities may be caused by the differences in preform structures and measurement errors.

Fiber architecture is an important parameter which will significantly affect the properties of the composites. The average values of the flexural strength for 2.5D (shallow 
TABLE-2

MECHANICAL PROPERTIES OF THE 2.5D QUARTZ/SILICA COMPOSITES

\begin{tabular}{lcccc}
\hline \multicolumn{1}{c}{ 2.5D composite types } & Density $\left(\mathrm{g} / \mathrm{cm}^{3}\right)$ & Tensile strength $(\mathrm{MPa})$ & Flexural strength $(\mathrm{MPa})$ & Shear strength $(\mathrm{MPa})$ \\
\hline Shallow bend-joint & 1.77 & 22.7 & 50.3 & 22.4 \\
Shallow straight-joint & 1.70 & 24.5 & 48.4 & 18.0 \\
\hline
\end{tabular}

straight-joint) specimen and 2.5D (shallow bend-joint) specimen were 48.4 MPa and 50.3 MPa, respectively. According to the principle of fiber-reinforced composites, the fiber volume fraction is the most important parameter to the performance of composite. Because the difference of fiber volume fraction between these two types of composites was very small and the flexural strength represent the overall performance of the composite, in most of the cases. The difference of the flexural strength between 2.5D (shallow straight-joint) specimen and 2.5D (shallow bend-joint) specimen was small. The average values of the shear strength for 2.5D (shallow straight-joint) specimen and 2.5D (shallow bend-joint) specimen were 18.0 $\mathrm{MPa}$ and 22.4 $\mathrm{MPa}$, respectively. The flexural strength and shear strength of 2.5D (shallow bend-joint) $\mathrm{Q}_{\mathrm{f}} / \mathrm{S}$ composites were superior to that of $2.5 \mathrm{D}$ (shallow straight-joint) $\mathrm{Q}_{\mathrm{f}} / \mathrm{S}$ composites.

However, unlike the flexural strength and the shear strength, the tensile strength of the 2.5D (shallow bend-joint) $\mathrm{Q}_{\mathrm{f}} / \mathrm{S}$ composites was inferior to that of $2.5 \mathrm{D}$ (shallow straightjoint) $\mathrm{Q}_{\mathrm{f}} / \mathrm{S}$ composites. The tensile strength of composites is closely dependent on the fiber content which is aligned in the direction of an applied force. Because the warp yarn of $2.5 \mathrm{D}$ (shallow straight-joint) preform was interlaced with every three weft yarns along the weaving direction and the warp yarn of 2.5D (shallow bend-joint) preform was interlaced with every two weft yarns. Fig. 2 shows the schematic diagram of tensile force of the warp yarns. The angle contained by the warp yarn with the horizontal plane of the 2.5D (shallow bend-joint) $\mathrm{Q}_{\mathrm{f}} /$ $\mathrm{S}$ composites $\left(\theta_{\mathrm{b}}\right)$ was greater than that of $2.5 \mathrm{D}$ (shallow straight-joint) $\mathrm{Q}_{\mathrm{f}} / \mathrm{S}$ composites $\left(\theta_{\mathrm{s}}\right)$. The stress components of the warp yarn along the horizontal direction of the $2.5 \mathrm{D}$ (shallow bend-joint) $\mathrm{Q}_{\mathrm{f}} / \mathrm{S}$ composites $\left(\mathrm{F}_{\mathrm{b}}\right)$ was less than that of 2.5D (shallow straight-joint) $\mathrm{Q}_{\mathrm{f}} / \mathrm{S}$ composites $\left(\mathrm{F}_{\mathrm{s}}\right)$ (Fig. 2). Thus, The tensile strength of 2.5D (shallow straight-joint) $\mathrm{Q}_{\mathrm{f}} / \mathrm{S}$ composites were superior to that of $2.5 \mathrm{D}$ (shallow bend-joint) $\mathrm{Q}_{\mathrm{f}} / \mathrm{S}$ composites.

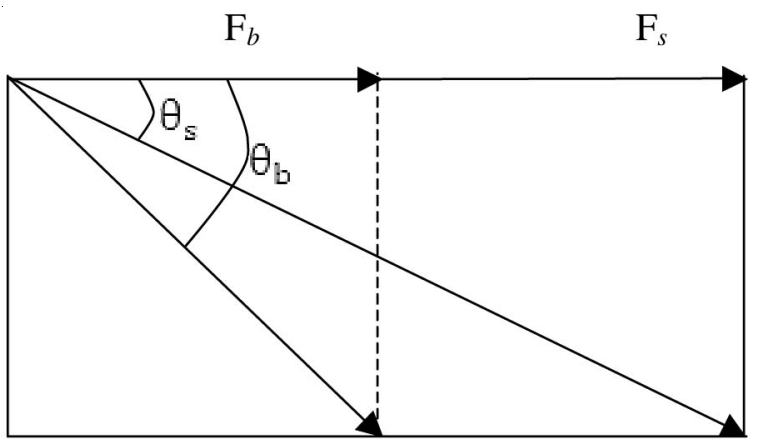

Fig. 2. Schematic diagram of tensile force of the warp yarns

The above results clearly indicate that the mechanical properties of these two kinds of 2.5D $\mathrm{Q}_{\mathrm{f}} / \mathrm{S}$ composites were different. Fig. 3 shows the histogram of the mechanical properties of $2.5 \mathrm{D}$ composites. The difference of fiber volume fraction between these two types of composites was very small. The fiber volume fraction is an important parameter which will affect the mechanical properties. However, in the instance of small difference of fiber volume fraction, the fiber placement will impact the mechanical properties and the failure behaviour of the composites significantly.

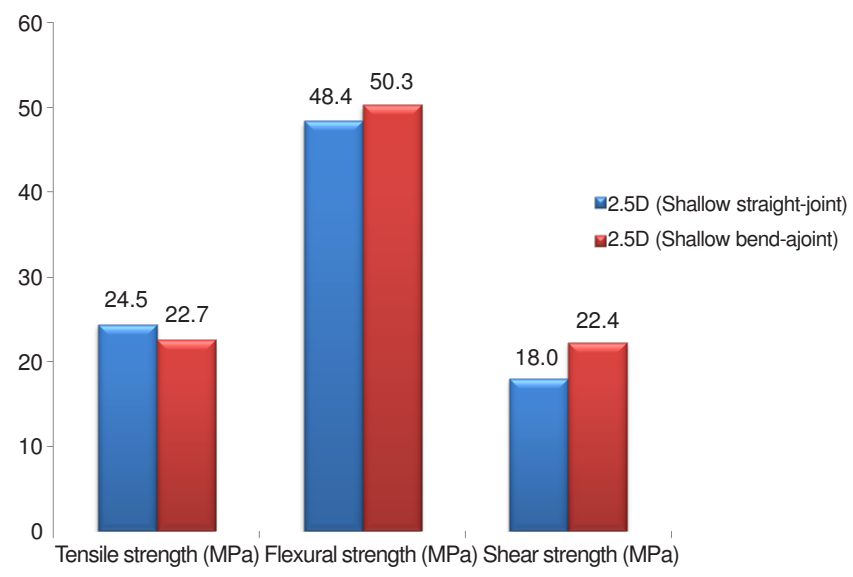

Fig. 3. Histogram of the mechanical properties of 2.5D composites

\section{Conclusion}

(1) $2.5 \mathrm{D}$ (shallow bend-joint) quartz/silica composite had a higher flexural strength and shear strength than $2.5 \mathrm{D}$ (shallow straight-joint) quart $\mathrm{f}_{\mathrm{f}} /$ silica composite.

(2) The fiber placement affects the mechanical properties of the composites significantly. The tensile strength of $2.5 \mathrm{D}$ (shallow straight-joint) quart $\mathrm{z}_{\mathrm{f}} /$ silica composites were superior to that of $2.5 \mathrm{D}$ (shallow bend-joint) quartz $/$ silica composites.

\section{ACKNOWLEDGEMENTS}

This work was supported by the Basic Research Project of Science and Technology of Jiangsu Province (No. BK2009002) and Funding of Jiangsu Innovation Program for Graduate Education (No. CXLX11_0188).

\section{REFERENCES}

1. P.F. Becher, J. Am. Ceram. Soc., 74, 255 (1991).

2. W.J. Clegg, K. Kendall, N.M. Alford, T.W. Button and J.D. Birchall, Nature, 347, 455 (1990).

3. N.E. Prasad, S. Kumari, S.V. Kamat, M. Vijayakumar and G. Malakondaiah, Eng. Fract. Mech., 71, 2589 (2004).

4. N.E. Prasad, D. Loidl, M. Vijayakumar and K. Kromp, Scripta Mater., 50, 1121 (2004).

5. C.-M. Xu, S.W. Wang, X.X. Huang and J.K. Guo, Ceram. Int., 33, 669 (2007).

6. Y.D. Xu, L.F. Cheng, L.T. Zhang, H.F. Yin and X.W. Yin, Mater. Sci. Eng. A, 318, 183 (2001).

7. P. Lipetzky, G.J. Dvorak and N.S. Stoloff, Mater. Sci. Eng. A, 216, 11 (1996). 
8. Y. Xu, L. Cheng, L. Zhang, H. Yin and X. Yin, Mater. Sci. Eng. A, 300, $196(2001)$

9. J.Q. Ma, Y.D. Xu, L.T. Zhang, L.F. Cheng, J.J. Nie and N. Dong, Scripta Mater, 54, 1967 (2006).

10. Z.G. Liu, F. Zhang, Z. Wu and G.Q. Tao, Chin. J. Aeronaut., 23, 61 (2010)

11. N. Jekabsons and J. Varna, Mech. Compos. Mater, 37, 289 (2001).

12. G. Boitier, J. Vicens and J.L. Chermant, Mater. Sci. Eng. A, 279, 73 (2000).

13. G. Boitier, J.L. Chermant and J. Vicens, Mater. Sci. Eng. A, 289, 265 (2000).

14. G. Boitier, J. Vicens and J.L. Chermant, Mater. Sci. Eng. A, 313, 53 (2001).
15. H.-K. Liu and C.-C. Huang, J. Eur. Ceram. Soc., 21, 251 (2001).

16. Y. Liu, J.X. Zhu, Z.F. Chen, Y. Jiang, C.D. Li, B.B. Li, L. Lin, T.R. Guan and Z.H. Chen, Ceram. Int., 38, 795 (2012).

17. Y. Liu, J.X. Zhu, Z.F. Chen, Y. Jiang, B.B. Li, L. Lin, T.R. Guan, X.N. Cong and C.D. Li, Mater. Sci. Eng. A, 532, 230 (2012).

18. Y. Liu, J.X. Zhu, Z.F. Chen, Y. Jiang, B.B. Li, Z.H. Chen, L. Lin, T.R. Guan and C.D. Li, Sci. Eng. Compos. Mater., 19, 55 (2012).

19. H. Chen, L.M. Zhang, G.Y. Jia, W.H. Luo and S. Yu, Key Eng. Mater, 249, 159 (2003).

20. S.A. Han, K.H. Jiang and J.W. Tang, Adv. Mater. Res., 79-82, 1767 (2009). 